\title{
CRIMINALIDADE E AS AUDIÊNCIAS DE CUSTÓDIA EM RONDÔNIA: O DESAFIO DO DESENCARCERAMENTO.
}

Criminality and the Custody Hearing in Rondônia: The Challenge of Non-incarceration.

Patrícia Mara Cabral de Vasconcellos ${ }^{1}$

Kerley Regina Ferreira de Arruda Alcântara²

Resumo: O artigo analisa o cenário do encarceramento e da criminalidade em Rondônia e, em que medida, as audiências de custódia contribuem para evitar a prisão aplicando, quando possível, as medidas cautelares substitutivas das penas privativas de liberdade. A pesquisa pautase em estudo de caso com a observação de 177 solenidades realizadas pelo Núcleo de Audiência de Custódia da comarca de Porto Velho, capital de Rondônia. Através dos dados coletados foi possível analisar o perfil social do custodiado, os tipos penais recorrentes e as decisões proferidas pelo juiz de custódia. Diante de um cenário de violência e desigualdade social, os critérios para a manutenção da prisão são principalmente a reincidência e a gravidade do delito. No entanto, notou-se que não há uma uniformidade de procedimentos entre os magistrados. Para além, há uma forte correlação entre prisão e justiça. Assim, em Rondônia, estado onde a criminalidade e o encarceramento em massa são marcas da violência urbana, reavaliar as alternativas e tecer medidas de aprimoramento dos institutos deve ser uma prática constante, inclusive no que se diz respeito às referidas audiências.

Palavras-chaves: encarceramento; audiência de custódia, criminalidade, Porto Velho, Rondônia.

Abstract: In this article, we analyze incarceration and criminality in Rondônia and the extent to which custody hearings prevent arrest by applying, where possible, precautionary measures instead of prison sentences. This research is based on a case study wherein 177 solemnities realized by the Nucleus Custody Hearing in the comarca of Porto Velho, capital of Rondônia, were

\footnotetext{
1 Doutora em Relacionais Internacionais pela Universidade de Brasília (UnB). Mestra em Relações Internacionais pelo Programa San Tiago Dantas. Bacharel em Ciências Sociais pela Unicamp. Professora do Departamento de Ciências Sociais da Universidade Federal de Rondônia (Unir). Professora do Programa de Mestrado em Direitos Humanos e Desenvolvimento da Justiça da Universidade Federal de Rondônia (Unir). Pesquisadora da Rede de Pesquisa em Política Externa e Regionalismo (REPRI). Atualmente, realiza o estágio pós-doutoral na Universidade de Santa Maria no Programa de Pós Graduação em História. Universidade Federal de Rondônia. Brasil. URL: https://orcid.org/0000-0002-9077-8734 E-mail: pmcvasconcellos@gmail.com

${ }^{2}$ Mestra em Direitos Humanos e Desenvolvimento da Justiça e magistrada no Tribunal de Justiça do Estado de Rondônia. Instituição: Tribunal de Justiça do Estado de Rondônia. Brasil. URL: https://orcid.org/00000002-2288-7787 E-mail: kerleyalcantara@gmail.com
} 
observed. The data revealed the social profiles of the custodians, recurring criminal types, and the decisions of the custody judge. Faced with violence and social inequality, the magistrates primarily use recidivism and the seriousness of the crime to determine if imprisonment will be maintained. However, procedural non-uniformity was noted between magistrates. Additionally, the correlation between imprisonment and justice was strong. Thus, in Rondônia, a state where urban violence is marked by crime and mass incarceration, the society should constantly reassess alternatives and improve the institutions, including these hearings.

Keywords: incarceration, custody hearing, criminality, Porto Velho, Rondônia.

\section{INTRODUÇÃO}

Os objetivos propostos com a implantação da audiência de custódia no Brasil estão relacionados a dois problemas, um deles é o encarceramento em massa de pessoas, o outro, a prevenção da prática de tortura institucionalizada. Neste artigo, busca-se avaliar em que medida as audiências de custódia alcançam o primeiro objetivo citado, ou seja, o de contribuir para evitar a prisão aplicando, quando possível, as medidas cautelares substitutas das penas privativas de liberdade. A pesquisa pauta-se em estudo de caso com a observação ${ }^{3}$ de 177 solenidades realizadas pelo Núcleo de Audiência de Custódia da comarca de Porto Velho, capital de Rondônia.

O aumento de pessoas encarceradas é reflexo de uma série de características que vão desde a ausência de políticas públicas capazes de frear a desigualdade e as situações de vulnerabilidade social até a proeminência de um modelo punitivista que alarda a insegurança social baseada em um perfil criminoso. Neste contexto, a prisão de pessoas surge como a principal via para o combate à criminalidade.

No período de 2005 a 2016, a população prisional brasileira cresceu 6,6\% em média ao ano (Pimenta, 2018). Com uma população carcerária de 726.712 pessoas em 2016, o Brasil foi o terceiro país que mais encarcerou no mundo, estando a sua frente somente os Estados Unidos e a China. O número de pessoas presas em 2016 no Brasil é o dobro das que se encontram nesta situação em 2005, isto é, 316,4 mil pessoas. Rondônia insere-se neste cenário com a

\footnotetext{
${ }^{3} \mathrm{O}$ formulário base utilizado para a observação foi idealizado pelos professores Rodrigo Griringhelli de Azevedo (PUCRS-FBSP) Jacqueline Sinhoretto (UFSCAR) que foram diretamente consultados e prestaram a devida orientação para preenchimento. Foram realizados ajustes ao formulário para adequá-lo a realidade local. Para conhecer a pesquisa realizada pelos autores fundamentada no formulário ver: AZEVEDO, Rodrigo Griringhelli (Coord). Produto Final - Audiência de Custódia, Prisão Provisória e Medidas Cautelares: Obstáculos Institucionais e Ideológicos à Efetivação da Liberdade como regra. São Paulo: Fórum Brasileiro de Segurança Pública, 2017. Contrato 17/2016 CNJ.
} 
particularidade de estar em uma região amazônica marcada por constantes conflitos agrários e mortes violentas. Em 2016, Rondônia foi considerado o terceiro estado que mais encarcerou proporcionalmente no Brasil (INFOPEN, 2016).

Contudo, no ano de 2015, o Conselho Nacional de Justiça editou a Resolução no 213/2015 regulamentando as audiências de custódia em todos os tribunais brasileiros, com a promessa de ser um freio ao encarceramento em massa de pessoas e prevenir a tortura policial. A referida resolução promoveu o controle de compatibilidade das normas de processos penais brasileiros e as normas internacionais que compunham o ordenamento jurídico desde 1992, como a Convenção Americana sobre os Direitos Humanos (Pacto de São José da Costa Rica de 1969) e o Pacto Internacional de Direitos Civis e Políticos (1966).

Dessa forma, as audiências de custódia colocaram-se como mais um passo para repensar a prisão como modelo de resolução social. Neste fato, alicerça-se a importância de conhecer as dificuldades de sua execução e resultados. Assim, em Rondônia, estado onde a criminalidade e o encarceramento em massa são marcas da violência urbana, reavaliar as alternativas e tecer medidas de aprimoramento dos institutos deve ser uma prática constante, inclusive no que se diz respeito às referidas audiências.

$\mathrm{Na}$ perspectiva dessa problemática, primeiramente busca-se contextualizar a criminalidade e os dados sobre o encarceramento em Rondônia e, em especial, Porto Velho. Posteriormente, avaliam-se os desafios da audiência de custódia diante da cultura do encarceramento. Por fim, apresentam-se os dados coletados na pesquisa de campo sobre o perfil e as decisões proferidas nas audiências de custódia realizadas na comarca da capital de Rondônia.

\section{CRIMINALIDADE E VIOLÊNCIA URBANA EM RONDÔNIA.}

Antes de atentar para os objetivos das audiências de custódia e seus resultados julga-se necessário explicitar o contexto que as envolve. Assim, primeiramente apresenta-se um quadro geral sobre a situação penal em Rondônia com relação ao encarceramento em massa, o perfil do custodiado e os crimes cometidos.

A violência urbana em Rondônia, assim como nos demais estados do Brasil, aliada ao aumento do medo e da sensação de insegurança por parte dos cidadãos, gerou uma política de encarceramento em massa. Contudo, a prisão vista como processo de justiça é, também, reprodutora da violência e tem evocado episódios que atestam a falência do regime disciplinar. 
No Brasil, casos marcantes como o massacre do Carandiru (1992) e, recentemente as mortes nos presídios de Manaus em $2017^{5}$ e $2019^{6}$ retratam a recorrência das condições inadequadas do cárcere e das violações de direitos humanos.

Em Rondônia o quadro repete-se. A casa de Detenção José Mário Alves ou "Urso Branco", em Porto Velho, já foi palco de rebeliões e mortes. Em uma delas, em janeiro de 2002, vinte e sete presos foram mortos. Por este caso, o Brasil foi denunciado na Comissão Interamericana de Direitos Humanos. A denúncia não impediu que as mortes no Urso Branco tornassem a ocorrer. Em junho no mesmo ano, mais dez detentos foram mortos. Em abril de 2004, aproximadamente trezentos visitantes foram feitos reféns em nova rebelião. No motim que durou cinco dias (de 18 a 23 de abril), doze detentos foram mortos com extrema violência e o presídio ficou parcialmente destruído (GIUNCHETTI, 2010).

Em 2011, na tentativa de reverter o quadro de violações e atender as recomendações da Corte Interamericana de Direitos Humanos, o governo do estado de Rondônia formula o "Pacto para melhoria do sistema prisional do estado de Rondônia e levantamento das medidas provisórias outorgadas pela Corte Interamericana de Direitos Humanos". No documento o estado reconhece que os principais problemas do sistema prisional são: o déficit de vagas, o déficit de investimento em infraestrutura, a qualificação insuficiente do quadro de pessoal, o crescimento da população carcerária em índice superior à média nacional, dentre outros (RONDÔNIA, 2011).

Na tabela a seguir (tabela 1) é possível verificar que, segundo o levantamento realizado pelo Monitor da Violência, no ano de 2015, a taxa de superlotação no sistema prisional de Rondônia é de $63,1 \%$, porcentagem próxima à identificada na média nacional $(65,8 \%)$ no mesmo ano. Em 2017, a taxa do estado de Rondônia é alarmante, chegando a quase 80\% acima da capacidade de vagas. Contudo, em 2019, há uma significativa queda para 40\% na taxa de superlotação. Sem o aumento do número de vagas, as hipóteses para a queda da taxa residem no aumento da porcentagem de presos provisórios, na política de patrulhamento ou mesmo nas decisões proferidas pelas audiências de custódia.

Tabela 1: O sistema prisional em Rondônia

\footnotetext{
${ }^{4}$ Em reprimenda a uma rebelião na Casa de Detenção de São Paulo, em 02 de outubro de 1992, houve a intervenção da Política Militar do Estado de São Paulo. O conflito resultou na morte de 111 detentos.

${ }^{5}$ Cinquenta e seis pessoas foram mortas no Complexo Penitenciário Anísio Jobim (Compaj), em uma rebelião que se iniciou no dia 1 de janeiro de 2017 e teve a duração de dezessete horas.

${ }^{6}$ Cinquenta e cinco pessoas foram mortas nos presídios de Manaus, entre os dias 26 e 27 de maio de 2019. As mortes ocorreram no Complexo Penitenciário Anísio Jobim e em outros três presídios - Centro de Detenção Provisória Masculina 1, Unidade Prisional do Puraquequara e Instituto Penal Antônio Trindade. Os assassinatos foram motivados pela rivalidade de facções criminosas - Família do Norte e Primeiro Comando da Capital.
} 


\begin{tabular}{|rrrrrrr}
\hline Rondônia & Superlotação & Número de presos & Número de Vagas & Provisórios & Número de Provisórios \\
\hline 2015 & $63,10 \%$ & 9.764 & 5.985 & $21,80 \%$ & 2.131 \\
\hline 2017 & $79,90 \%$ & 11.257 & 6.257 & $14,50 \%$ & 1.629 \\
\hline & 2019 & $40,00 \%$ & 7.929 & 5.665 & $21,10 \%$ & 1.676 \\
\hline \multicolumn{3}{|c|}{ Superlotação } & Número de presos & Número de Vagas Provisórios & Número de Provisórios \\
\hline & 2015 & $65,80 \%$ & 615.933 & 371.459 & $38,60 \%$ & 237.703 \\
\hline 2017 & $69,20 \%$ & 668.182 & 394.835 & $37,10 \%$ & 247.748 \\
\hline 2019 & $69,30 \%$ & 704.395 & 415.960 & $35,90 \%$ & 252.533 \\
\hline
\end{tabular}

Fonte: Elaboração própria com base em Monitor da Violência 2015/2017/2019.

Neste sentido, Santos e Marques (2019) destacam que a superlotação ocorre devido à inter-relação de polícias militares e Judiciário, com uma polícia que prende mais e com um sistema judiciário que mantem a prisão. Assim, afirmam os autores:

Entre os eixos a serem considerados na engrenagem que move esse sistema superlotado encontra-se a relação estabelecida entre as polícias militares, responsáveis pelo patrulhamento ostensivo nas ruas e pela alta produtividade de prisões em flagrante, e o Judiciário, que tem reiteradamente optado pela manutenção dessas prisões (Santos e Marques, 2019, s/n)

Paralelamente, nota-se que o número de prisões provisórias no Brasil demonstra que a excepcionalidade não é observada como regra pelo sistema de justiça brasileira. Com base nos dados apresentados pelo Monitor da Violência, aproximadamente 39\% da população carcerária brasileira, em 2015, consistia em presos provisórios. Rondônia é o estado da federação que tem a menor taxa de encarceramento provisório, em torno de 16\%, em 2017, o que é um dado positivo se comparado ao restante do país, mas que exige efetivo fortalecimento das audiências de custódia para melhoria do cenário. Em termos comparativos, em 2017, a segunda menor taxa de encarceramento provisório é do Distrito Federal com 22,8\% do total de presos e a maior é a registrada no Piauí, com 65\% de provisórios (MONITOR DA VIOLÊNCIA, 2017).

De acordo com a pesquisa realizada por Pimenta (2018), há um movimento de desencarceramento em vários países, como Estados Unidos, China e Rússia, mas o Brasil tem se movido na direção inversa, aumentando a sua taxa de aprisionamento. O autor cita como exemplo o fato da taxa de encarceramento, entre 2008 a 2016, ter crescido 56\% no Brasil e declinado 12\% nos Estados Unidos. Como já mencionado, entre os estados que mais encarceram no Brasil está Rondônia. Segundo as informações do Infopen (2017), Rondônia apresenta a terceira maior taxa de encarceramento proporcionalmente do país -606,1 presos a cada 100 mil habitantes. Em primeiro lugar está o estado do Mato Grosso do Sul $(696,7)$ seguido pelo estado do Acre $(656,8)$. 
O perfil geral do custodiado no sistema penitenciário de Rondônia é formado predominantemente pelo gênero masculino, aproximadamente 93\%, sendo a maioria jovem de 18 a 29 anos, com ensino fundamental incompleto, de cor parda, com penas que variam de quatro até oito anos (SEJUS, 2017). Na visão de Garland (2008), a seletividade penal é um fenômeno que acompanha o encarceramento em massa, pois ao lado do aumento do aprisionamento está a focalização do perfil criminoso em grupos sociais específicos. No caso do Brasil, a seletividade é marcada pelas características da juventude e do racismo. Pimenta (2008) reitera que para a experiência brasileira o conceito de encarceramento em massa deve ser entendido atentando-se para o perfil do aprisionado. Assim, apresenta a seguinte definição:

[...] encarceramento em massa é o processo pelo qual se promove, em ritmo acelerado, a privação de liberdade de um enorme contingente de pessoas com perfil específico, sobretudo jovens, negros e pobres, levado a cabo por políticas de segurança pública orientadas para a criminalização e o aprisionamento seletivo, cumprindo as funções de controle e contenção voltados à manutenção de estruturas sociais desiguais e excludentes (PIMENTA, 2018, p.184)

Apesar disso, conhecer as especificidades de cada região contribui para pensar alternativas e práticas, reconhecendo os riscos de uma análise pautada na homogeneidade que pode subjugar arranjos políticos e históricos singulares, conforme alerta Sinhoretto et al (2013) ao citar Wacquant (2001) e Garland (2008).

No que concerne ao crime cometido, destaca-se no cenário do estado de Rondônia e sua capital Porto Velho, o alto índice de estupros e de roubos ou furtos de veículos. Em ambos os casos, para os anos de 2016 e 2017 as taxas apresentadas por 100 mil habitantes são superiores a média nacional com exceção da taxa de estupro no ano de 2017, em Rondônia (Tabela 2). 0 crime de tráfico de entorpecentes apresenta-se abaixo da taxa nacional. Especificamente, na capital Porto Velho, os dados são inquietantes se comparados à média nacional na proporção a cada 100 mil habitantes. Por tal prisma, notam-se as taxas de estupros e de roubos ou furtos de veículos são mais do que o dobro da porcentagem apresentada nacionalmente. Já a taxa por mortes violentas intencionais é superior em 2016 e muito próxima em 2017. Cabe ainda destacar, a queda nos índices apresentados sobre os crimes elencados na cidade de Porto Velho de 2016 a 2017, fomentando a hipótese de menor patrulhamento ou atuação de políticas públicas. 
Tabela 2: Criminalidade Brasil, Rondônia e Porto Velho.

\begin{tabular}{|c|c|c|c|c|c|c|c|c|c|c|c|c|c|c|}
\hline \multirow{2}{*}{ Brasil } & \multicolumn{2}{|c|}{$\begin{array}{l}\text { Núm ero } \\
\text { Absol uto }\end{array}$} & \multicolumn{2}{|c|}{$\begin{array}{c}\text { Taxa por } \\
100 \text { mil } \\
\text { habitantes }\end{array}$} & \multirow{2}{*}{ Rondônia } & \multicolumn{2}{|c|}{$\begin{array}{l}\text { Número } \\
\text { Absoluto }\end{array}$} & \multicolumn{2}{|c|}{$\begin{array}{c}\text { Taxa por } \\
100 \text { mil } \\
\text { habitantes }\end{array}$} & \multirow{2}{*}{ Porto Velho } & \multicolumn{2}{|c|}{$\begin{array}{l}\text { Número } \\
\text { Absoluto }\end{array}$} & \multicolumn{2}{|c|}{$\begin{array}{c}\text { Taxa por } 100 \\
\text { mil } \\
\text { habitantes }\end{array}$} \\
\hline & 2016 & 2017 & 2016 & 2017 & & 2016 & 2017 & 2016 & 2017 & & 2016 & 2017 & 2016 & 2017 \\
\hline Mortes violentas intencionais & 61.597 & 63.895 & 29,9 & 30,8 & & 586 & 508 & 32,8 & 28,1 & & 191 & 159 & 37,4 & 30,6 \\
\hline Estupros & 55.070 & 61.032 & 26,7 & 29,4 & & 790 & 941 & 44,2 & 52,1 & & 382 & 346 & 74,7 & 66,6 \\
\hline Roubos e furtos de veículos & 557.504 & 543.991 & 595,5 & 561,5 & & 5.475 & 4.230 & 604,6 & 449,4 & & 3.291 & 2.832 & 1283,7 & 1069,2 \\
\hline Tráfico de entorpecentes & 156.188 & 173.789 & 75,8 & 83,7 & & 1.019 & 1.125 & 57,0 & 62,3 & & 287 & $\mathrm{NI}$ & 56 & NI \\
\hline
\end{tabular}

Fonte: Elaboração Própria com base no Anuário Brasileiro de Segurança Pública 2018 e 2017.

$\mathrm{NI}=$ Não informado

De todo modo, a violência urbana tem como consequência um elevado número de vítimas, transformando o cotidiano e apartando os grupos sociais, além de promover uma descrença e desconfiança institucional (COELHO, 1988). Para Young (2015), o aumento da criminalidade também resulta no aumento da população encarcerada, pois as causas do crime em uma sociedade desigual e excludente (precariedade econômica e individualismo) reforçam reações baseadas em estigmatização e encarceramento.

O aprisionamento é a solução encontrada mundialmente para conter os impactos decorrentes da redução nos investimentos sociais. Contudo, gera maior impacto social, pois, amplia o empobrecimento social que concebe transformações maléficas, sendo insuficientes para conter a crescente onda de violência no mundo. Alternativas devem ser encontradas para conter o encarceramento de pessoas no Brasil, afinal, a Constituição Federal afirma que a prisão deve se resumir às excepcionalidades. Diante disso, a audiência de custódia se mostra um mecanismo que pode ser efetivo, se for realizada com enfoque nos direitos humanos.

Com tal contexto, as audiências de custódia, tendo como um dos objetivos reavaliar a necessidade da prisão assume a característica de uma política judicial que busca alternativas à prisão.

No mesmo ano (TJRO, 2015) em que foram instruídas nacionalmente, as audiências de custódia passam a ser executadas em Porto Velho. Atualmente, o estado de Rondônia realiza as audiências em todas as Comarcas do Estado, um grande feito para um tribunal de pequeno porte e com Comarcas situadas em locais distantes e de difícil acesso (TJRO, 2016), tais como, a cidade de Costa Marques que fica a $740 \mathrm{~km}$ da capital com trechos da via pública sem asfalto, fazendo divisa com a Bolívia. Na Comarca de Porto Velho podemos citar como exemplo as localidades do Baixo Madeira ${ }^{7}$, onde o transporte de pessoas e produtos são realizados por barcos.

\footnotetext{
7 É a denominação dada aos que moram nas localidades as margens do Rio Madeira.
} 
O cenário prisional e de criminalidade em Rondônia, conforme demonstrado pelos dados, refletem uma série de obstáculos a serem superados para garantir a segurança da população e uma política penal efetiva e justa. A seguir discutem-se os fundamentos que instituem as audiências de custódia e seus desafios.

\section{CULTURA DO ENCARCERAMENTO E AUDIÊNCIAS DE CUSTÓDIA: DESAFIOS.}

A audiência de custódia é o momento processual em que toda a pessoa presa deve ser levada, sem demora, perante a autoridade judiciária para fazer cessar uma violência e eventual ilegalidade na sua prisão. Configura-se como uma garantia convencional, com natureza preventiva. É também chamada de "audiência de garantia" e visa resguardar direitos essenciais da pessoa humana, tais como integridade física e liberdade.

Tal instituto está previsto na Convenção Americana sobre os Direitos Humanos, Pacto de São José da Costa Rica de 1969 e no Pacto Internacional de Direitos Civis e Políticos, aprovados no ano de 1966 pela Assembleia Geral das Nações Unidas. No Brasil, foram internalizadas pelos decretos no. 678 e 592, respectivamente, ambos no ano de 1992. Contudo, a primeira iniciativa de implantação das audiências de custódia ocorre somente em 2014, no Estado do Maranhão, disciplinada pelo Provimento n. 24/2014 da Corregedoria Geral de Justiça do Tribunal de Justiça daquele estado. Naquele momento, as audiências de custódia aconteciam somente em São Luiz, a capital maranhense, tendo como prazo para apresentação do custodiado de 48 horas (TJMA, 2014).

No restante do Brasil, as audiências de custódia foram implantadas após decisão da Ação Declaratória de Preceito Fundamental, medida cautelar n. 347 do Supremo Tribunal Federal, postulada pelo Partido Socialismo e Liberdade (PSOL). O resultado do ajuizamento foi o reconhecimento pelo Supremo Tribunal Federal do estado de coisas inconstitucionais do sistema penitenciário brasileiro, quando se determinou a implantação das audiências de custódia pelos tribunais brasileiros em 90 dias. (STF, 2015).

A resolução 213/2015 do CNJ disciplinou a implantação das Audiências de Custódia e compatibilizou o processo penal brasileiro com os tratados internacionais e convenções internacionais, voluntariamente, assumidos pelo país.

De modo prático, para que a audiência de custódia possa diminuir o encarceramento é importante evitar à prisão desnecessária de pessoa, que pelas circunstâncias pessoais e tipo de 
crime, possam ser aplicadas as medidas cautelares substitutas da prisão. No mais, é preciso reavaliar o sistema punitivo e conhecer o ciclo de desigualdades.

Com o mesmo objetivo de não encarcerar, houve uma reforma legislativa no Código de Processo Penal, em 04 de maio de 2011, Lei no 12.403/2011 (BRASIL, 2011). Para a prisão em flagrante e a prisão preventiva, com a alteração da redação do artigo 310 do Código de Processo Penal, estabelece-se a seguinte redação:

Ao receber 0 auto de prisão em flagrante, o juiz deverá fundamentadamente: I - relaxar a prisão ilegal, ou; || - converter a prisão em flagrante em preventiva, quando presentes os requisitos constantes do art. 312 deste Código, e se revelarem inadequadas ou insuficientes às medidas cautelares diversas da prisão, ou; III - conceder liberdade provisória, com ou sem fiança. Parágrafo único. Se o juiz verificar, pelo auto de prisão em flagrante, que o agente praticou o fato nas condições constantes dos incisos I a III do caput do art. 23 do Decreto-Lei n 2.848, de 7 de dezembro de 1940 - Código Penal, poderá, fundamentadamente, conceder ao acusado liberdade provisória, mediante termo de comparecimento a todos os atos processuais, sob pena de revogação. (BRASIL, 2011).

Os dados do Conselho Nacional de Justiça (CNJ) evidenciam que a alteração legislativa não se mostrou suficiente para conter o crescimento do encarceramento provisório de pessoas, pois, os números aumentaram sensivelmente ao longo dos anos. Independentemente de as causas da pouca efetividade das medidas cautelares substitutivas da prisão, essa foi a motivação mais forte para a determinação das audiências de custódia no sistema processual penal brasileiro, pelo Supremo Tribunal Federal, na medida cautelar $n^{\circ} 347$, da relatoria do Ministro Marco Aurélio (STF, 2015).

No julgamento acima mencionado, o relator Min. Marco Aurélio afirmou que no Brasil existe uma "cultura do encarceramento", que associa a prisão como solução para conter a violência e um modelo de prevenção à prática de novos delitos.

Reprimir a violência com a prisão é uma diretriz decorrente do neoliberalismo, na qual os Estados reduzem os investimentos em programas sociais voltados a corrigir as desigualdades sociais e ampliam o aparato repressivo. David Garland esclarece que na década de 1970 o aumento da criminalidade na maioria dos países gerou o crescimento da sensação de insegurança das pessoas, levando a intensificação do encarceramento para retirar os criminosos de circulação (GARLAND, 2008). Gerou-se o endurecimento penal e das formas de contenção de pessoas, tendo como exemplo mais marcante os Estados Unidos que no início do século XXI tinha dois milhões de presos, uma taxa de 715 por 100 mil habitantes, enquanto em 1985, a taxa era de 200 
e a metade disso, no início dos anos de 1970 (SALLA e LOURENÇO, 2005, p. 330). Em outros termos, isto significa que a prisão passou a ser vista como meio primordial para dar segurança à sociedade.

No Brasil não houve uma mera cópia dos padrões e modelos estrangeiros, mas um processo histórico que se apresentou de forma particular combinando o liberalismo com a tradição escravocrata (SILVA, 1997). A preocupação sempre esteve na contenção de parcela da população composta por escravos ou homens e mulheres livres, mas pobres (MAIA, 2017), tanto que os açoites e a pena de morte estavam previstos no Código Criminal de 1830 e ainda está presente no inconsciente motivando a seletividade penal que encarcera os negros, jovens e pobres.

Dessa forma, o encarceramento em massa é a alternativa aplicada em várias nações para conter a miséria, subjugando os investimentos nos programas sociais para efetivamente combater a criminalidade. Consequentemente, o aumento do encarceramento é uma forma de controle social do miserável. No mundo inteiro percebe-se a mesma clientela de pessoas presas, ou seja, em maioria temos jovens e negros, como bem explicita Wacquant sobre o encarceramento em massa norte-americano:

Em nossos dias, o aparelho carcerário americano desempenha um papel análogo com respeito aos grupos que se tornaram supérfluos ou incongruentes pela dupla reestruturação da relação social e da caridade do Estado: as frações decadentes da classe operária e os negros pobres da cidade (WACQUANT, 2011, p. 104).

No mais, a precariedade e violência do cárcere reforça a conclusão de Michel Foucault (1997) de que a prisão atinge o objetivo pretendido com a sua criação, de gerar delinquente. Ela traz a identidade ao criminoso, na forma de falar, vestir, comportar-se, como aduz o autor: "A prisão torna possível, ou melhor, favorece a organização de um meio de delinquente, solitários entre si, hierarquizados, prontos para todas as cumplicidades futuras" (FOUCAULT, 1997, p. 261).

A prisão além de não produzir as transformações sociais necessárias para conter a criminalidade, reforça elementos culturais e comportamentais que estigmatizam e empobrecem o custodiado. Um levantamento realizado na França demonstra que $60 \%$ dos egressos permanecem sem emprego quando colocados em liberdade. Tal como, $12 \%$ continuam sem teto e mais de 1/4 não dispõe de dinheiro nem mesmo para a locomoção (WACQUANT, 2011, p. 153). Assim, a vulnerabilidade com que ingressou no sistema carcerário é maior quando o deixa, levando a novas práticas delitivas e a reincidência. Segundo estudos do Instituto de Pesquisa Econômica Aplicável, fundação pública vinculada à Secretaria de Assuntos Estratégicos da 
Presidência da República, a taxa de reincidência no Brasil é de 70\%, mostrando que a prisão, no Brasil, não atinge o caráter ressocializador pretendido (IPEA, 2015).

Os investimentos sociais no Brasil foram reduzidos nos últimos anos, se comparados com os investimentos em unidades prisionais. Um estudo realizado pelo Instituto de Pesquisa Luiz Flávio Gomes, por meio de dados do Instituto de Pesquisa Econômica Aplicada (IPEA) apontou que no período compreendido entre 1994 e 2009, o Brasil obteve uma queda de 19,3\% no número de escolas públicas do país, já que em 1994 havia 200.549 escolas públicas contra 161.783 em 2009. Em contrapartida, no mesmo período, o número de presídios aumentou 253\%. Isto porque, se em 1994 eram 511 estabelecimentos, este número mais que triplicou em 2009, com um total de 1.806 estabelecimentos prisionais (BORGES e GUIMARÃES, 2013).

Assim, verifica-se que a diminuição do investimento social no Brasil foi substituída pelo encarceramento, inclusive essa lógica se fez presente na Constituição Federal quando estabeleceu normais penais acerca dos crimes hediondos, no artigo 5o, inciso XLIII, impedindo a concessão de fiança, anistia e graça aos autores (Monteiro Neto, 2018). Sabidamente, a massificação do encarceramento começa com a prisão em regime integralmente fechado para os crimes hediondos, nos quais o tráfico foi equiparado.

A conjuntura descrita anteriormente por si só é um desafio para que se obtenham resultados positivos da audiência de custódia. Além disso, entre as dificuldades que podem ser enumeradas está a resistência, por parte dos magistrados para a sua realização, em especial, no que a doutrina chama de "transpor a fronteira do papel" (Flausino, 2017). Olhar além do papel significa que o custodiado deixa de ser alguém mencionado em um documento, para se transformar em sujeito que tem direito à voz, ao mesmo tempo em que o juiz é transportado do "ser distante e frio", para "ouvidos" que estão prontos para escutar e sensíveis aos relatos apresentados.

Assim, um dos propósitos da audiência de custódia é promover a humanização das relações estabelecidas entre o Poder Judiciário e o encarcerado, assegurando que a pessoa presa seja entrevistada pelo Juiz, sob a fiscalização de Promotores de Justiça e Defesa (advogado ou defensor público). É uma das poucas oportunidades em que o custodiado falará sobre as circunstâncias em que se realizou a sua prisão em flagrante delito, logo após a sua prisão, ou seja, no calor dos acontecimentos, possibilitando que providências sejam tomadas e as provas sejam produzidas. A próxima ouvida do preso será no interrogatório. No Brasil deveria ser o máximo de 
81 dias $^{8}$, mas pode variar de procedimento criminal, bem como a multiplicidade de réus e atos a ser realizados, tais como, cartas precatórias.

Por este prisma, o encaminhamento do custodiado à presença de um juiz promove uma quebra de paradigmas, pois, obriga o juiz a uma reformulação de postura, muitas vezes fria e distante, para uma mais próxima e sensível. Essa mudança foge a tradição clássica que faz parte da formação do magistrado e dificulta a aceitação do ato entre os membros da mencionada classe. No mais, o contato com os fatos narrados pelo preso é uma oportunidade de reavaliar o contexto da ação, reconhecer particularidades, situações de vulnerabilidade social e barrar a formação do estigma.

Em que pese à resistência da magistratura acerca da realização da audiência de custódia, dela o Poder Judiciário não pode se furtar, tanto que em alguns estados vêm ocorrendo à expansão para o interior. Ainda em 2015, vários estados já implantavam o projeto "Audiência de Custódia" em municípios do interior, dentre eles: Espírito Santo, Maranhão, São Paulo, Roraima, Mato Grosso e Paraná (ANDRADE e ALFLEN, 2016).

As audiências de custódia são um pequeno passo diante das inúmeras políticas públicas que devem ser realizadas para alterar a desigualdade social e o quadro de criminalidade no Brasil. Certamente, as audiências de custódia não são a solução para o desencarceramento, mas revelam a expectativa de uma nova postura do Judiciário. Sua efetividade depende desde uma mudança cultural e comportamental do magistrado até uma atenção burocrática e normativa quanto ao seu rito.

\section{NA PORTA DE ENTRADA DO SISTEMA CRIMINAL DE JUSTIÇA.}

Quem se encontra na porta de entrada do sistema criminal de justiça? Quais têm sido as decisões proferidas nas audiências de custódia? É possível aprisionar menos? Para responder tais questões foram observadas 177 solenidades realizadas pelo Núcleo de Audiência de Custódia (NUPC) de Porto Velho e analisadas as atas das referidas audiências. O período de observação ocorreu na segunda semana de cada mês, durante os meses de dezembro de 2017 a março de 2018.

\footnotetext{
${ }^{8}$ Considera-se a soma de todos os atos previstos no Código de Processo Penal, no procedimento de crimes apenados com reclusão, de competência do juiz singular. O prazo foi obtido por construção jurisprudencial.
} 
Quem é o custodiado? A pesquisa buscou apurar o perfil sócio econômico daquele apresentado à audiência de custódia com base nas seguintes características: gênero, cor ou raça, idade, trabalho, moradia e se possuem antecedentes criminais. Quanto ao gênero, às informações coletadas apontam que $91 \%$ dos presos são homens, $8 \%$ são mulheres e $1 \%$ de transgêneros femininos, sem registro de trans. masculinos. Quanto à cor ou raça observou-se que $44 \%$ dos presos são pardos e $40 \%$ são pretos, ou seja, $84 \%$ foram identificadas como negros ${ }^{9}$. 0 maior percentual de negros custodiados no país (AZEVEDO, 2017). Dos demais ouvidos pelo juízo de garantia $14 \%$ são brancos e $2 \%$ são indígenas.

Em todo Brasil tem-se que o encarceramento de negros e pardos é maior que de brancos. Realidade interpretada como existência de uma seletividade penal e filtragem racial (ADORNO, 1994; AZEVEDO, 2017) nas prisões efetuadas. Essa seletividade da justiça criminal no Brasil advém da acentuada predileção ou direcionamento das ações decorrentes do poder de polícia às pessoas negras e pobre (WOLF in VITTO e DAUFEMBACK, (ORG), 2018).

Em Porto Alegre, por exemplo, embora a maioria da população seja branca, a maioria dos presos que passam na audiência de custódia é negra. Os negros somam 13\% da população do Rio Grande do Sul (IBGE, 2010). Contudo, segundo pesquisa realizada por Azevedo (2017), 56\% das pessoas que foram ouvidas nas audiências de custódia em Porto Alegre, capital gaúcha, foram de negros, deixando clara a vinculação racial que envolve as prisões naquele estado.

A presença expressiva de negros na Comarca de Porto Velho justifica-se, parcialmente, pelo processo histórico da região, quando no início do século XIX com o ciclo da borracha, associado ao movimento político da Cabanagem, consolidou-se a presença negra no leste da Amazônia brasileira, dedicada a uma economia agrícola baseada na exploração da mandioca, milho e arroz. Segundo o Censo 2010, a população da capital rondoniense é composta por 29.964 pessoas que se autodeclararam pretas (7\%), e 262.843 pessoas pardas (61\%), 124.375 brancos (29\%) e 2.189 indígenas (1\%). Utilizando-se o padrão da pesquisa ${ }^{10}$, são $68 \%$ de negros na capital rondoniense.

Sobre a idade, na pesquisa realizada pelo Fórum Brasileiro de Segurança Pública, em todas as capitais pesquisadas, a maioria das prisões envolve os jovens, sendo que a idade de maior incidência de pessoas presas é de 18 anos, 20\% têm menos de 20 anos e metade tem até 30 anos (AZEVEDO, 2017).

\footnotetext{
${ }^{9}$ Utiliza-se a classificação do IBGE que somam a categoria de pretos e pardos para indicar a quantidade de negros.

${ }^{10}$ Considera-se para fins desse artigo os negros como sendo a raça composta por pessoas pretas e pardas.
} 
A idade das pessoas presas ouvidas no núcleo em Porto Velho confirma a predileção pela juventude, tendo a maior incidência entre os 18 a 24 anos. Neste contexto, demonstra-se que na comarca de Porto Velho o perfil dos encarcerados é o mesmo do restante do Brasil sendo jovens negros. Embora a população de pessoas negras seja a maioria na capital de Rondônia e, assim, faça com que a seletividade penal não esteja tão evidente, é importante reforçar os apontamentos sobre a problemática.

A questão racial envolve diferentes ângulos da criminalidade e violência. Está presente no número de mortes violentas no Brasil, evidenciada pelo "Mapa da Violência: Os jovens do Brasil" (2012). Assim, por exemplo, a população jovem é o alvo crescente de mortes violentas no país, existindo um aumento de homicídios entre negros e a redução entre brancos (SINHORETTO e MORAIS, 2017).

Enquanto os jovens negros aparecem como a maior parte de vítimas em homicídio envolvendo policiais, amplia-se a estatística de prisões em todo o Brasil, reforçando a conclusão, de Salo de Carvalho (2015), que a ampliação do encarceramento visa criar um modelo políticoeconômico que busca neutralizar "guetos de consumidores falhos" (CARVALHO, 2015, p. 140).

Segundo Sinhoretto e Morais (2017) os atributos pessoais pesam no imaginário policial e em todo o sistema de justiça e, em razão disto, cresce o número de pessoas negras no cárcere. Os dados do Mapa do Encarceramento, no período de 2005 a 2012, apontam para o fato dos negros serem presos 1,5 vezes a mais do que brancos (BRASIL, 2015). Ao realizar uma pesquisa sobre a filtragem racial nas abordagens policiais, Sinhoreto (2014) descreve que os policiais entrevistados negavam que o fator cor ou raça estivesse relacionado ao "tipo suspeito", mas, por outro lado, afirmavam que o tipo de vestimenta e a postura corporal era o que ditava quem ia ser abordado. Para a pesquisadora, esse critério demonstra uma ligação de cunho racial, pois, a forma de andar e vestir estão associados a "cultura de periferia". Fato é que a "atitude suspeita" está na maioria das vezes ligada a motivação preconceituosa.

Isto não significa que os policiais ou quaisquer outras autoridades que componha o sistema de justiça criminal sejam conscientemente preconceituosos ou racistas. O que se afirma é que fazem parte de uma engrenagem que promove discriminação e desigualdade, principalmente por ser esta mesma população que é vítima da exclusão e da falta de investimentos sociais. Certamente, a naturalização das atitudes impede uma visão crítica sobre a formação do comportamento e da cultura.

Quanto ao trabalho, constatou-se no núcleo da audiência de custódia que 20\% dos casos apresentados não foram questionados sobre ter ocupação lícita, mesmo sendo uma das informações requeridas para o preenchimento da base de dados denominada de Sistema 
de Audiência de Custódia (SISTAC) e sendo uma condição que pode influenciar na concessão da liberdade provisória dos mesmos. Dos que foram questionados, $16 \%$ não responderam ao magistrado qual a sua ocupação e 19\% afirmaram não trabalhar. Contudo, não foi possível demonstrar se não tinham profissão ou se os custodiados estavam desempregados. A maioria dos flagranteados ouvidos está trabalhando na informalidade, sem vínculo empregatício. Estavam nesta condição aproximadamente $36 \%$ dos observados. Apenas $8 \%$ dos presos tinham empregos formais.

A maioria dos presos (54\%) ouvidos na audiência de custódia em Porto Velho informou possuir residência fixa própria. Não foi possível identificar se os segregados são detentores de propriedade ou se moram em imóvel cedido por familiares. Pesquisa realizada em outros estados, como a realizada por Azevedo (2017), revela que a maioria dos juízes fazem perguntas sobre a condição de residência, pois, tais informações são consideradas relevantes para a apreciação de possível soltura. Entretanto, em Porto Velho, em 24\% dos casos não houve questionamento por parte do magistrado se o flagranteado tinha domicílio certo e em $19 \%$ não foi informado se havia ou não residência.

No último critério que compõe o perfil do custodiado tem-se que na comarca de Porto Velho, 32\% dos presos não informaram a existência de antecedentes ao serem questionados pelo juiz. Daqueles que responderam ao questionamento do magistrado, $40 \%$ tinham antecedentes e $21 \%$ não contavam com outros registros de envolvimentos delituosos.

Os antecedentes criminais são explorados pelos magistrados, sendo um dos fatores mais relevantes para a decretação da prisão preventiva em Porto Velho. Nos estados analisados pelo Fórum Brasileiro de Segurança Pública constatou-se que 51\% das pessoas detidas tinham passagens criminais anteriores. 39\% dos ouvidos não tinham registros de envolvimentos em outros delitos. Em $10 \%$ dos casos não foi objeto de interesse dos juízes saber sobre os antecedentes dos custodiados (AZEVEDO, 2017).

Diante das audiências observadas, conclui-se que o perfil das pessoas presas que passam na audiência de custódia é de homens jovens, negros. A maioria, embora não reincidente, possui antecedentes criminais. Estão trabalhando na informalidade e não pagam aluguel.

Qual foi a decisão dos juízes das audiências? A pesquisa revelou que 54\% dos presos ouvidos na audiência de custódia em Porto Velho tiveram a prisão em flagrante convertida em prisão preventiva, sendo que $46 \%$ obtêm decisões de liberdade provisória. Saliente-se que no período da pesquisa, ou seja, 11 de dezembro de 2017 a 09 de março de 2018, foram efetuadas 
1308 prisões $^{11}$ (RONDONIA, POLÍCIA CIVIL. 2018), dos quais somente 567 pessoas foram ouvidas nas audiências de custódia, ou seja, 741 pessoas ou aproximadamente 56,6\% dos indivíduos foram colocadas em liberdade antes da solenidade por meio das decisões dos juízes plantonistas ou pagamento de fiança na própria delegacia de polícia ${ }^{12}$ (TJRO, 2018).

Neste caso, com base nos dados coletados, das 1308 prisões efetuadas tem-se que em torno de $76,5 \%$ das pessoas não foram imediatamente encarceradas ${ }^{13}$. Todas as decisões judiciais concessivas de liberdade aos entrevistados em audiência de custódia foram vinculadas a uma medida cautelar substitutiva a prisão, sendo que na maioria dos casos foi adotada a fiança, seguida da proibição de acesso a determinados lugares, frequência a locais como alcoólicos anônimos (AA) e narcóticos anônimos (NA), ausentar-se da Comarca enquanto responder a ação penal ou comparecimento periódicos em juízo.

É possível prender menos? Influem diretamente na decisão do juiz o critério da reincidência e o tipo de crime. Como visto, na Comarca de Porto Velho, 32\% dos presos não informaram a existência de antecedentes. Daqueles que responderam $40 \%$ dos presos tinham antecedentes. Já os reincidentes eram $18 \%$ das pessoas apresentadas. As prisões preventivas na Comarca de Porto Velho-RO guardam relação com o número de pessoas com histórico de envolvimento em outras práticas delituosas.

Outro fato que repercute na quantidade de prisões é a natureza dos delitos praticados. O levantamento realizado por meio da observação das audiências de custódia retrata que a maioria dos delitos que levam as pessoas a prisão são os crimes patrimoniais. Os crimes de roubo e de tráfico de drogas somam mais de $36 \%$ dos crimes em tese praticados pelos inquiridos na custódia. Os crimes contra a pessoa mais recorrentes nas audiências de custódia de Porto Velho são decorrentes de violência doméstica com pouco mais de $16 \%$ dos casos e os homicídios tentados com mais de $2 \%$.

Dessa forma, entende-se que as decisões judicias que ordenaram a prisão do custodiado foram fundamentadas na existência antecedentes em 19\%, na manutenção da ordem pública em $15 \%$ e na gravidade concreta do delito em $9 \%{ }^{14}$.

\footnotetext{
${ }^{11}$ Os dados são da Central de Flagrantes e da Delegacia Especializada Narcóticos (02/08/2018), que são as duas unidades da polícia civil onde constam os maiores números de prisões em flagrante delito. Em Rondônia cada delegacia realiza o controle dos dados de prisão de forma descentralizada.

${ }^{12}$ As liberações havidas sem audiência de custódia não estão contempladas no presente levantamento.

${ }^{13}$ Das 1.308 pessoas presas, 56,6\% foram colocadas em liberdade antes da audiência de custódia. Após a audiência, uma média de $46 \%$ de presos foi colocada em liberdade provisória.

14 Tais informações foram retiradas da análise das atas de audiências das audiências de custódias observadas.
} 
Referências Bibliográficas:

ADORNO, Sérgio. Discriminação racial e justiça criminal em São Paulo. Novos estudos. CEBRAP, n. 43, p. $45-63$.

ANDRADE, Mauro Fonseca; ALFLEN, Pablo Rodrigo (orgs) Audiência de custódia : da boa intenção à boa técnica [recurso eletrônico]. Porto Alegre: FMP, 2016.

AZEVEDO, Rodrigo Griringhelli (Coord). Produto Final - Audiência de Custódia, Prisão Provisória e Medidas Cautelares: Obstáculos Institucionais e Ideológicos à Efetivação da Liberdade como regra. São Paulo: Fórum Brasileiro de Segurança Pública, 2017. Contrato 17/2016 CNJ.

BORGES, Paulo César Corrêa; GUIMARÃES, João Vitor Mello de Oliveira. O Sistema Penitenciário brasileiro como índice e medida do grau de civilização nacional. Direito \& Justiça v. 39, n. 1, p. 8393, jan./jun. 2013.

BRASIL. Lei $n^{0}$. 12.403 de 4 de maio de 2011. Altera dispositivos do Decreto-Lei $n=3.689$, de 3 de outubro de 1941 - Código de Processo Penal, relativos à prisão processual, fiança, liberdade provisória, demais medidas cautelares, e dá outras providências. Disponível em: <http://www.planalto.gov.br/ccivil_03/_ato2011-2014/2011/lei/l12403.htm>. Acesso em 16 abr. 2019.

BRASIL. Presidência da República. Secretaria Geral. Mapa do encarceramento: os jovens do Brasil/ Secretaria-Geral da Presidência da República e Secretaria Nacional de Juventude. - Brasília: Presidência da República, 2015. 112 p.: il. - (Série Juventude Viva).

CARVALHO, Salo. Criminologia cultural. In: LIMA, R. S. de; RATTON, J. L.; AZEVEDO, R. G. de. (Org.). Crime, polícia e justiça no Brasil. São Paulo: Contexto, 2014. p. 138-147.

CNJ [Conselho Nacional de Justiça]. Resolução № 213 de 15/12/2015. Disponível em: <http://www.cnj.jus.br/busca-atos-adm?documento=3059>. Acesso em 03 mar. 2019.

COELHO, E. C. A criminalidade urbana violenta. Dados, vol. 31, No 2, 1988, (145-183).

FLAUSINO, Camila Maués dos Santos. Audiência de Custódia e seus (in)sucessos - Breves críticas a seus descompassos práticos. Revista Liberdade. Ed. no24. Jul/2017. Instituto Brasileiro de Ciências Criminais.

GARLAND, David. A CULTURA DO CONTROLE: Crime e Ordem Social na Sociedade Contemporânea - Coleção Pensamento Criminológico № 16. Editora Revan: Rio de Janeiro, 2008.

GIUNCHETTI, Camila Serrano. Globalização e direitos humanos. Estudo acerca da influência da Corte Interamericana de Direitos Humanos sobre as Instituições Domésticas: o caso do Presídio "Urso Branco" (RO). Tese (Doutorado em Relações Internacionais) - Universidade de Brasília Instituto de Relações Internacionais. Brasília, 2010. 
IBGE [Instituto Brasileiro de Geografia e Estatística]. Censo Demográfico 2010. Disponível em: <https://censo2010.ibge.gov.br/>. Acesso em 4 mar. 2018.

INFOPEN. Levantamento nacional de informações penitenciarias. Atualização - junho de 2016/ Brasília: Ministério da Justiça e Segurança Pública. Departamento Penitenciário Nacional, 2017. $65 p$.

IPEA. Reincidência criminal no Brasil: relatório de pesquisa. Rio de Janeiro, 2015. Disponível em: http://www.ipea.gov.br/agencia/images/stories/PDFs/relatoriopesquisa/150611_relatorio_rein cidencia_criminal.pdf. Acesso em: 10 de abril de 2017.

MAIA, Clarisse Nunes (Org.). A história das prisões no Brasil. 1a ed. Rio de Janeiro: Anfiteatro, 2017. MONITOR DA VIOLÊNCIA. Raio X do sistema prisional em 2015. 05/2015. Disponível em: <http://especiais.g1.globo.com/politica/2015/raio-x-do-sistema-prisional/> Acesso em 5 abr. 2019.

MONITOR DA VIOLÊNCIA. Raio X do sistema prisional em 2017. 06/01/2017. Disponível em: < http://especiais.g1.globo.com/politica/2017/raio-x-do-sistema-prisional/> Acesso em 5 abr. 2019.

MONITOR DA VIOLÊNCIA. Raio X do sistema prisional em 2019. 26/04/2019. Disponível em: $<$ http://especiais.g1.globo.com/monitor-da-violencia/2019/raio-x-do-sistema-prisional/> Acesso em 5 abr. 2019.

MONTEIRO NETO, Figueiredo. Audiência de Custódia e a sua incapacidade de contenção do Poder Punitivo. UNIOESTE: Toledo-PR, 2018. Disponível em: <http://tede.unioeste.br/>. Acesso em 22 mai. 2018.

PIMENTA, Victor Martins. Por trás das grades: o encarceramento em massa no Brasil. Editora Revan, 2018.

RONDÔNIA. Pacto para melhoria do sistema prisional do estado de Rondônia e levantamento das medidas provisórias outorgadas pela Corte Interamericana de Direitos Humanos. 22/08/2011. Disponível em: <http://www.rondonia.ro.gov.br/pacto-para-melhoria-do-sistema-prisional-doestado-de-rondonia-e-levantamento-das-medidas-provisorias-outorgadas-pela-corteinteramericana-de-direitos-humanos/>. Acesso em: 20 mai. 2019.

RONDÔNIA. Polícia Civil do Estado de Rondônia. E-mail de 02/08/2018. Acervo pessoal. SALLA, Fernando Salla e LOURENÇO, Luiz Cláudio. Aprisionamento e prisões. In: LIMA, Renato Sérgio de; RATTON, José Luiz; AZEVEDO, Rodrigo Ghririnhelli de. (orgs). Crime, Polícia e Justiça no Brasil. 1. ed. São Paulo: Contexto, 2014. 
SANTOS, Thandara; MARQUES, David. Prisões superlotadas não inibirão o crime e a violência. Fórum Brasileiro de Segurança Pública, 26/04/2019. Disponível em: <https://g1.globo.com/monitor-da-violencia/noticia/2019/04/26/prisoes-superlotadas-naoinibirao-o-crime-e-a-violencia.ghtml>. Acesso em 10 mai. 2019. SEJUS [Secretaria de Estado da Justiça de Rondônia]. Panorama do Sistema Penitenciário do Estado de Rondônia em 2017. 2017. Disponível em: <data.portal.sistemas.ro.gov.br/2019/02/Panorama2017.pdf>. Acesso em 03 mar. 2019.

SINHORETTO, J. ; SILVESTRE, G. ; MELO, F. A. L. . O encarceramento em massa em São Paulo. Tempo Social (USP. Impresso), v. 25, p. 86, 2013.

Sinhoretto, Jacqueline e Danilo de Souza Morais. 2018. "Violência e racismo: novas faces de uma afinidade reiterada". Revista de Estudios Sociales 64: 15-26. https://doi.org/10.7440/res64.2018.02. Acesso em 10/12/2014.

SILVA. Mozart Linhares da Silva. Do império da lei às grades da cidade. Coleção História 15. EDIPUCRS. Impresso.1997.

STF [Supremo Tribunal Federal]. MEDIDA CAUTELAR NA ARGÜIÇÃO DE DESCUMPRIMENTO DE PRECEITO FUNDAMENTAL 347 DISTRITO FEDERAL. 09/09/2015. Disponível em: $<$ http://redir.stf.jus.br/paginadorpub/paginador.jsp?docTP=TP\&docID=10300665>. Acesso em 15 mai. 2018.

TJMA [Tribunal de Justiça do estado do Maranhão]. Provimento n 24/2014. 10/12/ 2014. Disponível em: <http://www.tjma.jus.br/cgj/visualiza/sessao/1559/publicacao/407902> Acesso em: 07 abr.2018.

TJRO [Tribunal de Justiça do estado de Rondônia]. NUAP. Relatório Estatístico. E-mail de 02/08/2018. Acervo pessoal.

TJRO [Tribunal de Justiça do estado de Rondônia]. Provimento no 001/2016 - Dispõe sobre a implantação das Audiências de Custódia nas Comarcas do interior do Estado de Rondônia. 22/02/2016. Disponível em: <https://www.tjro.jus.br/corregedoria/index.php/atosnormativos/provimentos/60-provimentos/provimentos-2016/1661-001-2006-cg.>. Acesso em 25 mai. 2018.

VITTO, Renato C.P de; DAUFEMBACK, Valdirene. (Org). Para além da prisão: reflexão e proposta para a nova política criminal no Brasil. Belo Horizonte (MG): Letramento: Casa do Direito, 2018. WACQUANT, Loïc.. As Prisões da Miséria. Tradução: TELLES, Andre. 2.Ed. Amp. Rio de Janeiro: Zahar, 2011. 
Nas decisões de prisão preventiva nos crimes de roubo observou-se que os magistrados procuram em várias situações enfatizar a necessidade da prisão para evitar que outras pessoas sejam vitimadas pela mesma prática delituosa, servindo de exemplos. Para grande parte dos juízes, a decretação da prisão é uma forma de combater a impunidade e ainda garantir a manutenção da credibilidade na Justiça, sendo que tais argumentos constam como fundamentação de decisões de prisão retiradas da análise das atas de audiências. Visualiza-se, conforme conceito tecido pelo ministro Marco Aurélio, a forma como a "cultura do encarceramento" (STF, 2015) se manifesta.

Em uma sociedade punitivista, o não prender abala a credibilidade do Judiciário. Neste caso, visualiza o ideário de que o aprisionamento confere uma noção de justiça social. Em outras palavras, a pena de prisão é a principal resposta do Poder Público para combater a criminalidade.

Para prender menos, deve-se compreender que a prisão não tem sido a solução para a violência no Brasil, pelo contrário, cada vez mais tem recriado e fortalecido ciclos de desumanização.

\section{CONSIDERAÇÕES FINAIS.}

Através dos dados coletados foi possível perceber o perfil social do custodiado, os tipos penais recorrentes e as decisões proferidas pelo juiz de custódia. Diante de um cenário de violência e desigualdade social, os critérios para a manutenção da prisão são principalmente a reincidência e a gravidade do delito. No entanto, notou-se que não há uma uniformidade de procedimentos entre os magistrados. Para além, há uma forte correlação entre prisão e justiça.

Durante as audiências de custódia o magistrado se coloca frente a frente com vários problemas sociais que demandam auxílio técnico especializado, entre eles a drogadição, medidas de segurança, andarilhos, além dos que demandam uma verificação social, tais como a situação dos filhos menores do encarcerado. Para um desencarcerar efetivo deve-se pensar em

\footnotetext{
WACQUANT, Loïc. Os condenados da cidade: estudo sobre marginalidade avançada. Editora Revan: Rio de Janeiro, 2001.

YOUNG, Jock. A Sociedade Excludente: Exclusão Social, Criminologia e Diferença na Modernidade Recente - Coleção Pensamento Criminológico no07. Editora Revan: Rio de Janeiro, $3^{\circ}$ edição, 2015.
} 
instituições de apoio que apontem novas perspectivas e rompam o ciclo da violação penal. Para além, deve-se refletir sobre o fortalecimento das medidas cautelares como um justo processo de reinserção social, retirando a prisão do centro do sistema penal.

Para que não seja apenas protocolar, todas as orientações normativas para a realização das audiências de custódia devem ser seguidas, sem as quais a sua efetividade para com os objetivos propostos fica comprometida.

As audiências de custódia são consideradas como um avanço, contudo, a sua efetividade demanda que elas sejam realizadas com total sintonia e com enfoque nos Direitos Humanos. Compete ao Poder Judiciário o papel de protagonismo no sistema de justiça criminal com uma postura que garanta os direitos fundamentais da pessoa humana, esteja ela presa ou não.

Trabalho enviado em 25 de junho de 2018

Enviado 30 de setembro de 2019 